\title{
Influence of Climate and Nonclimate Parameters on Monthly Electricity Consumption in Niger
}

\author{
Abdou Latif Bonkaney (iD \\ West African Science Service Center on Climate Change and Adapted Land Use, Faculte des Sciences et Techniques, \\ Universite de Niamey, Niger \\ Correspondence should be addressed to Abdou Latif Bonkaney; babdoulatif@yahoo.fr
}

Received 21 September 2019; Revised 30 November 2019; Accepted 3 February 2020; Published 1 March 2020

Academic Editor: Mohamed Benghanem

Copyright (c) 2020 Abdou Latif Bonkaney. This is an open access article distributed under the Creative Commons Attribution License, which permits unrestricted use, distribution, and reproduction in any medium, provided the original work is properly cited.

\begin{abstract}
This study examines the impacts of relevant factors (climatic and nonclimatic) on the monthly electricity consumption (MEC) in four major cities in Niger using simple multiple linear regressions (MLRs). Parameters such GDP/capita, air temperature (Tmean), relative humidity $(\mathrm{RH})$, wind speed (WSP), solar radiation (SR), precipitation, and clearness index (K) are used. In addition, two heat indices, heat index (HI) and discomfort index (DI) are calculated to take into account the impacts of high humidity in conjunction with high ambient temperature. Hence, three different models were derived from the aforementioned variables. The three models have been tested using the $k$-folds cross-validation. Results show that the model with primitive variables such GDP per capita, Tmean, RH, SR, and WSP perform better than the other two models with a coefficient determination $R^{2}$ equal to 0.87, 0.854, 0.833, and 0.551 for Niamey, Maradi, Zinder, and Agadez, respectively. According to the month considered, the mean absolute percentage error can give a small error for specific combinations of climate variables. The variables such as precipitation and clearness index are found to be not statistically significant.
\end{abstract}

\section{Introduction}

Investigating the influence of relevant factors on the electricity consumption is very important to derive a model that can predict the future energy consumption under changing climate. Indeed, one of the most vulnerable sectors to climate change and variability is the energy sector especially the electricity demand owing to the observed correlation between electricity demand and climate variables during hot periods. Hence, for a sustainable management of the energy sector under changing climate, there is a need to understand the factors that affect the electricity consumption. For instance, the electricity produced needs to be instantly consumed, as it cannot be stored. So, understanding the influence of climate and nonclimatic factors on electricity consumption will help to derive a robust model to face this challenge.

Energy demand is driven by both climate-related and socioeconomic factors [1-6]. Among the climate variables, the temperature is found to play the most important role that influences the electricity consumption [7-13].
Previous studies have found that the relationship between the electricity demand and the ambient temperature by using the temperature-derived parameters such the cooling degree days (CDD) and the heating degree days (HDD) to solve the problem of nonlinearity between the electricity demand and ambient temperature [14-18]. However, in addition to temperature variable, other primitive climate variables such as relative humidity, solar radiation, and wind speed may also influence the electricity consumption.

Moreover, socioeconomic factors including the gross domestic product, the population, the income, and the consumer behavior have also been found to influence the energy demand but at different timescales $[5,19,20]$.

Nevertheless, there is no study in Niger regarding the influence of climate and nonclimate factors on monthly electricity consumption. Hence, due to the fact that both the influence of climate and nonclimate factors on consumption depend on the specific location, there is a need to carry out such a study in order to help the policymakers in the energy 
sector to take informed decision in a context of continuous population growth and climate change.

In recent years, many models have been used to study both the influence of climate and socioeconomic parameters on electricity throughout the world. These models include the multiple linear regression (MLR) model, the artificial neural network (ANN), the principal component analysis (PCA), and the autoregressive integrated moving average (ARIMA) [21-25]. Among these models, the MLR presents advantages because it is easy to use and also easy to control since the inputs can be adjusted for each analysis [17, 26]. Hence, in this work, the impacts of climate variables and GDP per capita on the monthly electricity consumption in four major cities in Niger (Niamey, Maradi, Zinder, and Agadez) will be investigated using the MLR model. The climate data used include variables such as temperature, RH, WSP, $\mathrm{SR}, \mathrm{HI}$, and DI.

1.1. Electricity Data. A time series of monthly electricity consumption (MEC) in kWh, from January 2003 to October 2016 for the four cities in Niger (Niamey, Maradi, Zinder, and Agadez), have been used in this study. The data was obtained from the national agency for electricity (NIGELEC) [27]. The data comprise the aggregated electricity consumption for all the sectors including the residential, the commercial, and the industrial sectors as disaggregated data for individual sectors are not available. Figure 1 presents the electricity share of the different sectors in Niger in 2011. It is worth noting that the residential (household) sector presents the largest share $(74.98 \%)$ of the total electricity consumption in Niger (Figure 1).

The monthly electricity of each month is derived by the number of days within this month in order to remove the calendar effect.

The electricity consumption in the four cities depicts seasonal variation and an increasing trend (Figure 2). The latter could be attributed to the socioeconomic development while the former could be a result of weather fluctuations. The seasonal variation of electricity consumption can be examined with the monthly seasonal variation index defined in equation (1).

$$
\operatorname{MSVI}_{i j}=\frac{E_{i j}}{\underline{E j}},
$$

where $\mathrm{MSVI}_{i j}$ is the index value for month $i$ in year $j, E_{i j}$ is the energy consumption for month $i$ in year $j$, and the $E j$ is the average electricity consumption in year $j$.

The MSVI of the electricity consumption for the four cities is shown in Figure 3. From this figure, peaks and valleys can be noticed. For example, the MSVI for Niamey shows two distinct peaks in April-May and October corresponding to the hot months according to the climatology of the city. The high electricity consumption in these months is due to high cooling requirement and refrigeration. Minimum values of the consumption are obtained in December-February for all the four cities. This corresponds to the winter period where low solar radiation is obtained.

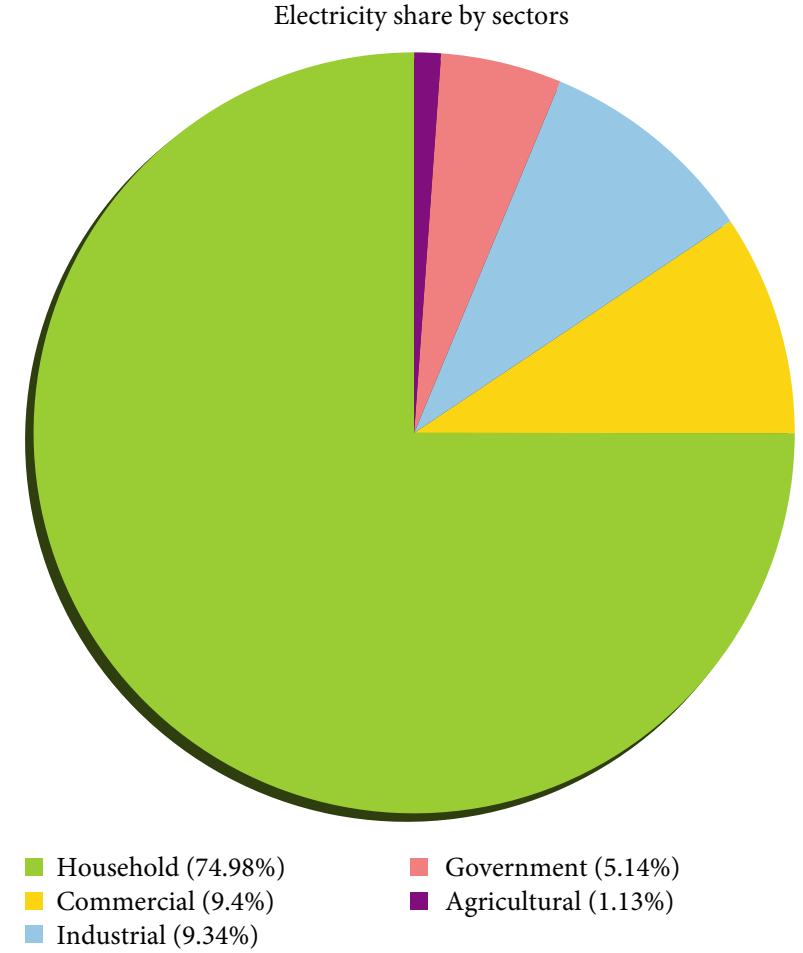

Figure 1: Total electricity share in Niger for the different consumption sectors in 2011 (source: NIGELEC, 2017).

1.2. Weather Variables. The weather variables used in this study consist of daily values of ambient temperature, relative humidity, wind speed, solar radiation, and clearness index. The ambient temperature and relative humidity data were obtained from the meteorological service in Niger while the solar radiation data were from the National Center for Solar Energy (CNES), Niamey. In addition to these variables, clearness index was computed using the following formula:

$$
K=\frac{\mathrm{GH}}{G 0},
$$

where $\mathrm{GH}$ is the horizontal global radiation and the $G 0$ is the radiation at the top of the atmosphere. The $G 0$ data were obtained from the NASA power agro climatology website [28].

In addition to these weather variables, two humiditytemperature indices, the heat index (HI) developed by Steadman [29] and the discomfort index (DI), are also calculated using equations (2) and (3), respectively.

$$
\begin{aligned}
\mathrm{HI}= & C_{0}+C_{1} * T+C_{2} * H+C_{3} * T H+C_{4} * T^{2}+C_{5} * H^{2} \\
& +C_{6} * T^{2} H+C_{7} * T H^{2}+C_{8} * T^{2} H^{2},
\end{aligned}
$$

where $\mathrm{HI}$ is the heat index, $T$ is the temperature in Fahrenheit, $H$ is the relative humidity in $\%$, and $C_{n}$ is the constants

$$
\mathrm{DI}=T-(0.55-0.0055 * H) *(T-14)
$$



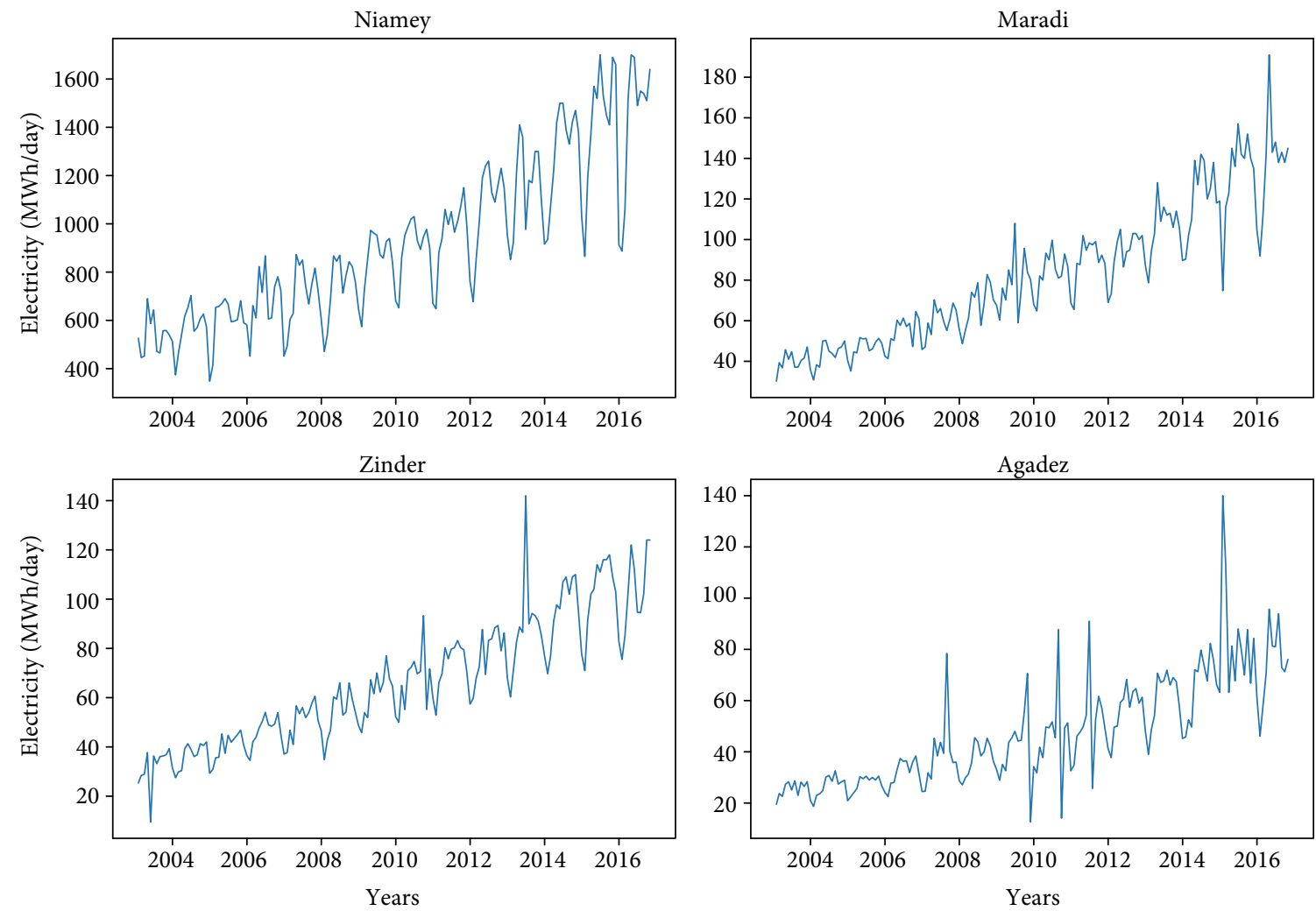

FIgUre 2: Monthly electricity evolution for Niamey, Maradi, Zinder, and Agadez from January 2003 to October 2016.
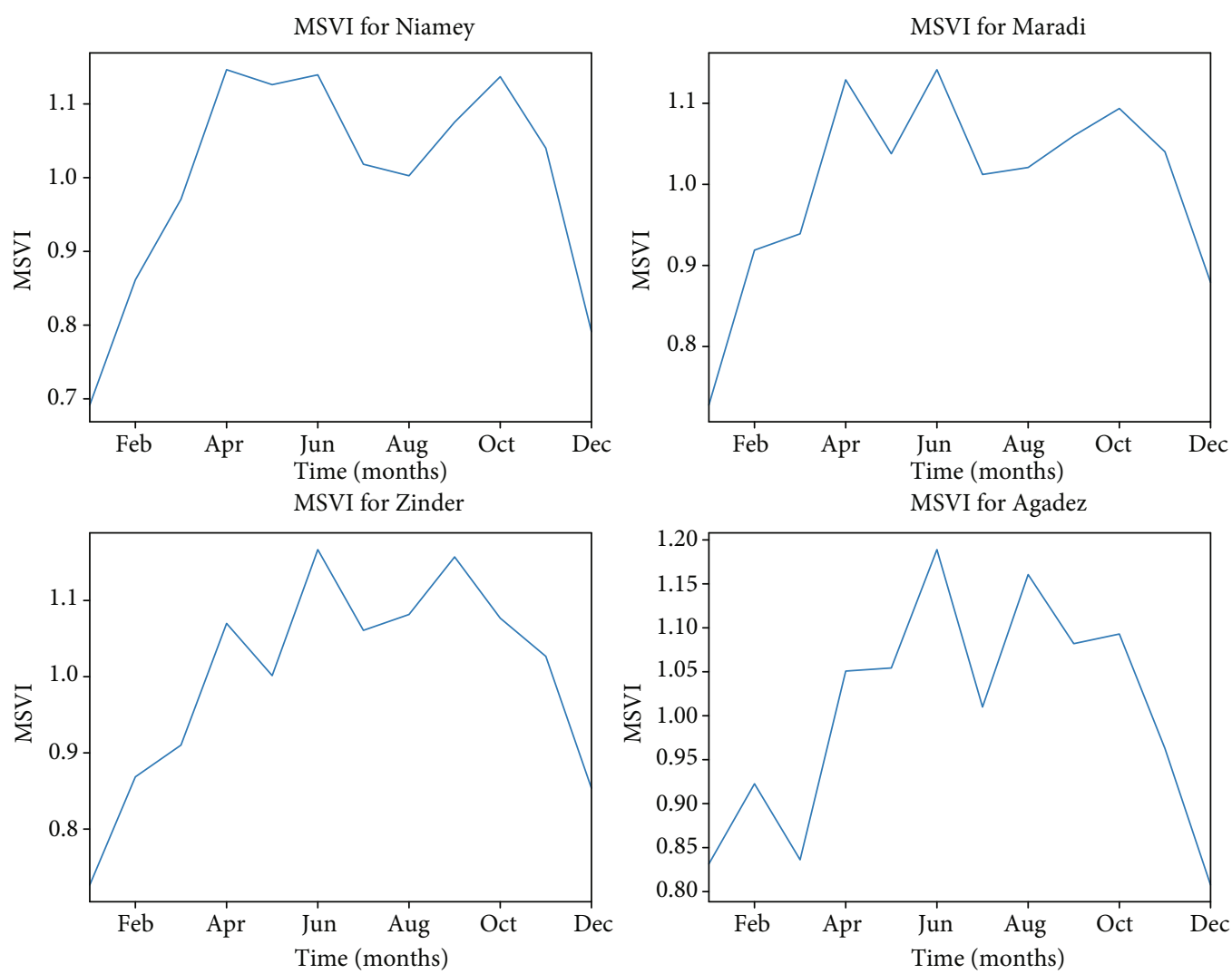

Figure 3: Monthly seasonal variation index of electricity for the four cities from January 2003 to October 2016. 

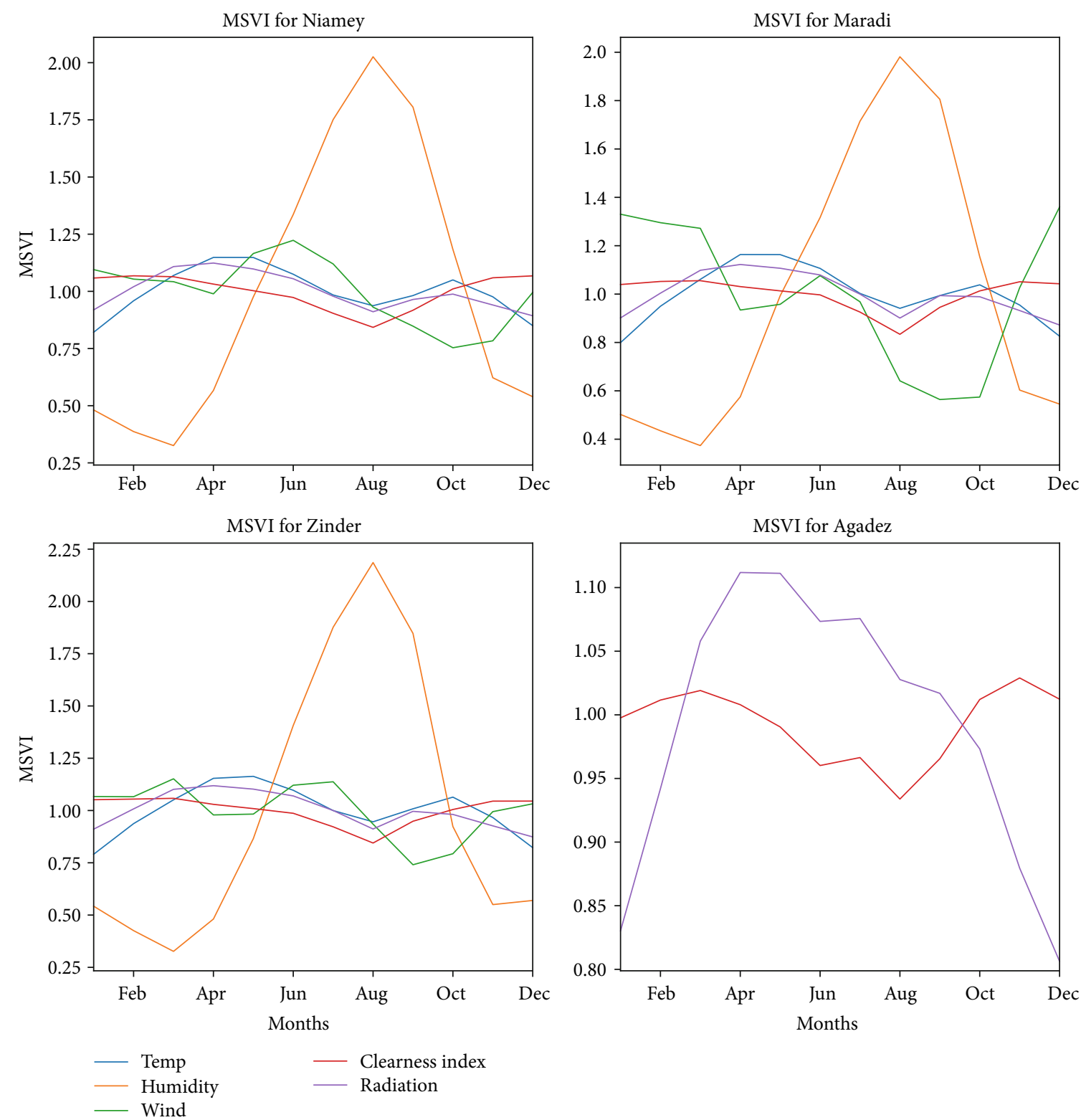

Figure 4: Monthly variation indices for the ambient temperature, humidity, wind, solar radiation, and clearness index from January 2003 to October 2016 for the four cities.

In addition to these variables, the socioeconomic parameter such as GDP/capita data has been also considered.

Figure 4 shows the annual cycle of the various climate variables considered in this study. For all the cities, high temperature values are observed in summer (March-May) with peaks in May while low values are in winter (December-February). Regarding the relative humidity, the maximum value is observed in August. This is due to the fact that the intertropical discontinuity (ITD) reaches its north most position in August. Looking at solar radiation, the same pattern of variation is obtained compared to temperature variable. Low values are obtained for DecemberFebruary and August. The low values in DecemberFebruary are a result of the winter season while in August, it is due to high cloudy conditions that blocks the incoming solar radiation [30].

Table 1 summarizes the relevant statistics for these weather variables.

\subsection{Methods}

1.3.1. Multiple Linear Regression Model. The multiple linear regression (MLR) models are used to investigate the correlation between the monthly energy demand with the weather parameters and the socioeconomic factors.

Prior to this, the influence of the population data has been removed by considering energy consumption per capita. Then, all the parameters were considered to build the MLR models. 
TABLE 1: Statistical summary of the weather variables used in this study.

\begin{tabular}{|c|c|c|c|c|c|c|c|c|c|c|c|c|c|c|c|c|}
\hline & \multicolumn{4}{|c|}{ Niamey } & \multicolumn{4}{|c|}{ Maradi } & \multicolumn{4}{|c|}{ Zinder } & \multicolumn{4}{|c|}{ Agadez } \\
\hline & Mean & Std & Max & Min & Mean & Std & Max & Min & Mean & Std & Max & Min & Mean & Std & Max & Min \\
\hline $\mathrm{T}\left({ }^{\circ} \mathrm{C}\right)$ & 30 & 3.1 & 36 & 22 & 29 & 3.5 & 35 & 19 & 30 & 3.6 & 36 & 21 & 32 & 4.5 & 38 & 21 \\
\hline RH (\%) & 35 & 21 & 79 & 8 & 38 & 21 & 84 & 11 & 30 & 19 & 72 & 8 & 21 & 11 & 53 & 6.9 \\
\hline $\mathrm{WSP}(\mathrm{m} / \mathrm{s})$ & 3.2 & 0.5 & 4.5 & 1.8 & 1.8 & 0.8 & 5.2 & 0.2 & 3.4 & 0.7 & 1.9 & 5.2 & 5 & 1.1 & 7.9 & 2.2 \\
\hline $\mathrm{SR}\left(\mathrm{MJ} / \mathrm{m}^{2} /\right.$ day $)$ & 22 & 1.9 & 27 & 19 & 23 & 2.1 & 27 & 18 & 23 & 2.1 & 18 & 28 & 23 & 2.5 & 28 & 18 \\
\hline K & 0.6 & 0.05 & 0.7 & 0.5 & 0.6 & 0.05 & 0.7 & 0.5 & 0.6 & 0.05 & 0.7 & 0.5 & 0.7 & 0.03 & 0.8 & 0.6 \\
\hline
\end{tabular}
below:

The general MLR model is formulated using the equation

$$
\mathrm{EC}=\beta_{0}+\sum_{i=1}^{n} \beta_{n} X_{n}+\varepsilon
$$

where $\mathrm{EC}$ is the monthly energy consumption; $\beta_{0}, \beta_{1}, \ldots \beta_{n}$ are the regression constants which are determined by the ordinary least squares method (OLS); $X_{1}, X_{2}, \ldots X_{n}$ are the independent variables; and $\varepsilon$ is the error term.

From this equation, we derive three different models given by the following.

The first model comprises all the primitive weather variables given by eq. (4)

$$
\begin{aligned}
\mathrm{EC}= & \beta_{0}+\beta_{1} * \mathrm{GDP}+\beta_{2} * \mathrm{Temp}+\beta_{3} * \mathrm{RH}+\beta_{4} * \mathrm{WSP} \\
& +\beta_{5} * \mathrm{SR}+\beta_{6} * \mathrm{prcp}+\beta_{7} * \mathrm{~K}+\varepsilon,
\end{aligned}
$$

where Temp, RH, WSP, SR, K, and GDP are the independent variables considered in this study.

In both model 2 and model 3 , the combined effect of temperature and $\mathrm{RH}$ has been taken into account by introducing DI and $\mathrm{HI}$, respectively.

$$
\begin{aligned}
\mathrm{EC}= & \beta^{\prime}{ }_{0}+\beta^{\prime}{ }_{1} * \mathrm{GDP}+\beta_{2}^{\prime} * \mathrm{DI}+\beta_{3}^{\prime} * \mathrm{WSP}+\beta_{4}^{\prime} * \mathrm{SR} \\
& +\beta_{5}^{\prime} * \operatorname{prcp}+\beta_{6} * \mathrm{~K}+\varepsilon, \\
\mathrm{EC}= & \beta^{\prime \prime}{ }_{0}+\beta^{\prime \prime}{ }_{1} * \mathrm{GDP}+\beta^{\prime \prime}{ }_{2} * \mathrm{HI}+\beta^{\prime \prime}{ }_{3} * \mathrm{WSP}+\beta^{\prime \prime}{ }_{4} \mathrm{SR} \\
& +\beta^{\prime \prime}{ }_{5} * \operatorname{prcp}+\beta^{\prime \prime}{ }_{6} * \mathrm{~K}+\varepsilon^{\prime \prime} .
\end{aligned}
$$

1.3.2. Model Validation. The MLR models are validated by using $k$-folds cross-validation. The $k$-fold cross-validation is mainly used to overcome the issues of overfitting in predictive modeling [31]. The $k$-folds cross-validation is performed by dividing the data into $k$ subsets (folds). Then, $k-1$ subsets corresponding to 9 subsets in this case were used to train the model and the last subset is left for testing.

The accuracy of the model was verified through the use of mean absolute percentage error (MAPE), and the coefficient of determination $R^{2}$ given by equations (9) and (10).
TABLE 2: $R^{2}$ for individual predictors and electricity consumption.

\begin{tabular}{lcccc}
\hline Variables & \multicolumn{4}{c}{ Coefficient of determination $R^{2}$} \\
& Niamey & Maradi & Zinder & Agadez \\
\hline Tmean & 0.318 & 0.21 & 0.135 & 0.123 \\
Humidity & 0.036 & 0.03 & 0.065 & 0.062 \\
Wind & 0.07 & 0.001 & 0.05 & 0.022 \\
Radiation & 0.051 & 0.04 & 0.016 & 0.035 \\
K & 0.07 & 0.009 & 0.068 & 0.082 \\
prcp & 0.08 & 0.001 & 0.036 & 0.052 \\
HI & 0.29 & 0.11 & 0.14 & 0.009 \\
DI & 0.01 & 0.01 & 0.001 & 0.005 \\
GDP & 0.51 & 0.7 & 0.69 & 0.42 \\
\hline
\end{tabular}

These metrics have been already used in several studies ([2, 32-34]; Yuan et al. [35]

$$
\begin{aligned}
\text { MAPE } & =\frac{100}{n} * \sum_{i=1}^{i=n}\left|\frac{O_{i}-P_{i}}{O_{i}}\right|, \\
R^{2} & =\frac{\sum_{i=1}^{n}\left(P_{i}-\bar{O}\right)^{2}}{\sum_{i=1}^{n}\left(O_{i}-\bar{O}\right)^{2}} .
\end{aligned}
$$

The $t$ test is also used to find out how significant each independent variable is in the regression model. The level of significance is set to 0.05 . In other words, all the variables with a $p$ value of less than 0.05 will be considered statistically significant.

\section{Results and Discussion}

2.1. Correlations between Per Capita Electricity Consumption and Parameters. The coefficients of determination $R^{2}$ between the energy consumption and the various parameters considered in this study are given in Table 2. From this table, GDP and temperature are the most influential parameters to the MEC. However, their relative contribution depends on the city. Indeed, the highest coefficient of determination $\left(R^{2}\right)$ between the MEC and GDP is found for the city of Maradi while the lowest is for the city of Agadez. This might due the ambient temperature which contributes more to MEC in Niamey than in the other cities. This can be attributed to the level of development of each area. Indeed, the electricity consumption in Niamey is more 
Actual and predicted values of MEC per capita

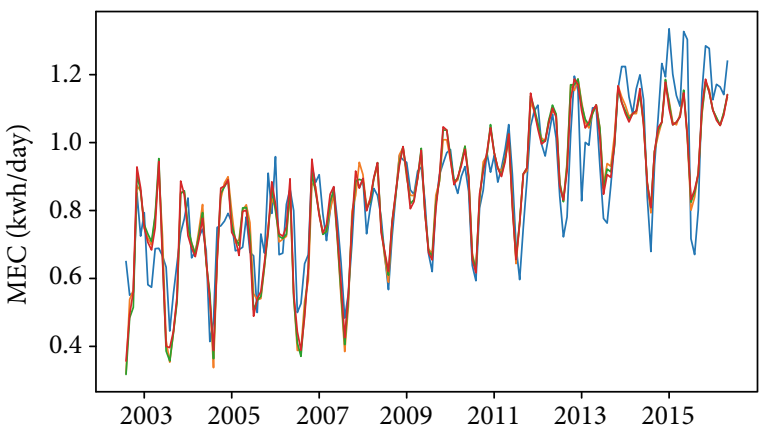

(a) Niamey

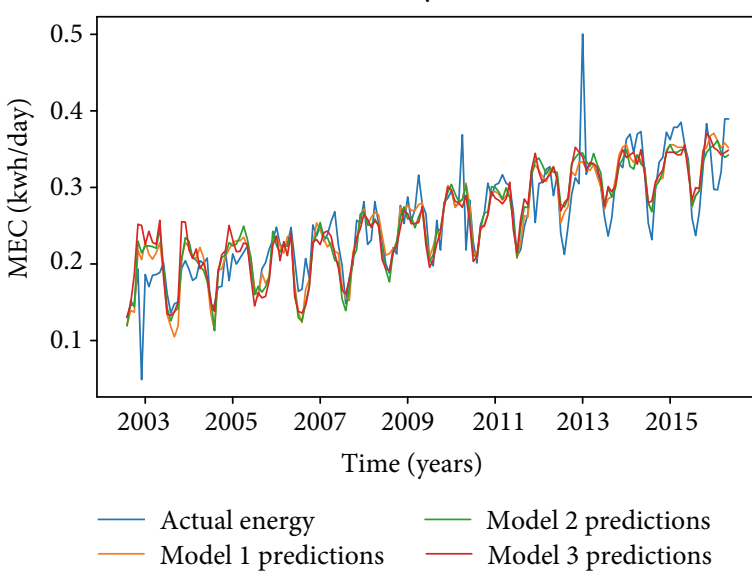

(c) Zinder

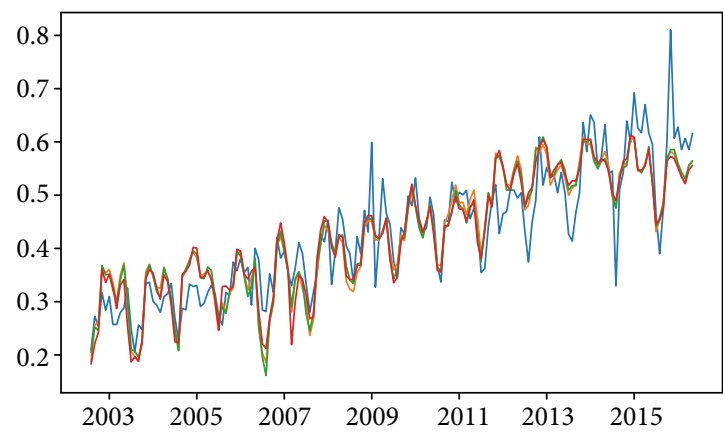

(b) Maradi

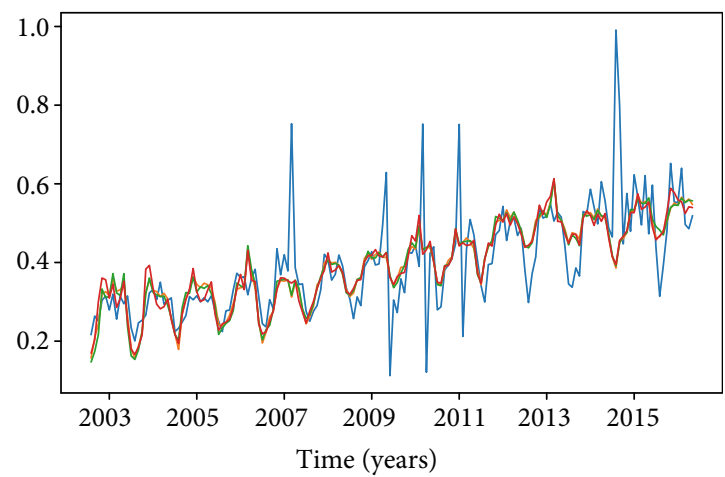

(d) Agadez

Figure 5: Actual and predicted values of per capita monthly consumption for Niamey, Maradi, Zinder, and Agadez.

influenced by weather variables than in the other cities because of the high number of air conditioning and refrigerators.

2.2. Multiple Linear Regression Results. Figure 5 shows the comparison between the actual and predicted per capita MEC for the four cities for model 1, model 2, and model 3. It can be noted that a close correspondence between the real and predicted MEC values, except for Agadez where a strong difference between the real predicted values of MEC, can be observed. This might be due to the fact that in this city, the electricity is more influenced by the mining activities that were not taken into consideration in any of the 3 models.

Based on the coefficient of determination $R^{2}$ and mean absolute percentage error (MAPE), model 1 performs better than models 2 and 3. Indeed, for Niamey, $87 \%$ of variability in MEC is explained by model 1 while models 2 and 3 explain, respectively, $85.4 \%$ and $78 \%$ of the variation in MEC. This is confirmed by the MAPEs, which are, respectively, $7.67 \%, 8.23 \%$, and $9.79 \%$ for model 1 , model 2 , model 3. These values go down for the other cities. Indeed, for Maradi, the $R^{2}$ values are $85.4 \%, 83.4 \%$, and $80 \%$, respectively, for model 1, model 2, and model 3. For Zinder, the $R^{2}$ values are, respectively, $83.3 \%, 78 \%$, and $83.3 \%$ for model 1 , model 2 , and model 3. However, for Agadez, the values further go down with $55.1 \%$ for model $1,54.9 \%$ for model 2 , and
$53.1 \%$ for model 3. Hence, for all the cities, model 1 performs better than the two other models.

Tables 3-5 show the regression results for model 1, model 2 , and model 3 , respectively. The different regression coefficients defined in equations (6)-(8) and their corresponding $p$ values were presented in these tables. Model 1 for Niamey shows that all the variables except the precipitation and clearness index are statistically significant at 95\% confidence level. However, for Maradi and Zinder, in addition to precipitation and clearness index, the wind speed is also found to be not statistically significant at $95 \%$ confidence level. These values are above the significant level set earlier. In contrast, only GDP and temperature are statistically significant at $95 \%$ confidence level in Agadez. All the other variables have $p$ values greater than 0.05 .

The residual error from the fitted regression models is the difference between the actual and predicted MECs as defined earlier in equations (6)-(8). The residual plot should be normally distributed to comply with the basic assumptions of regression models. The plots of residual errors obtained from the best MLR model for the four cities are shown in Figure 6. The plots show that there is no significance curvature and no major outliers for all the cities except Agadez where some outliers are observed. This confirms that there are not specific patterns between the residuals and observed independent variables. Therefore, we can conclude that the models comply with the multiple linear regression assumptions. 
Table 3: Results for model 1 for Niamey, Maradi, Zinder, and Agadez.

\begin{tabular}{|c|c|c|c|c|c|c|c|c|}
\hline \multirow{2}{*}{ Explanation variable } & \multicolumn{2}{|c|}{ Niamey } & \multicolumn{2}{|c|}{ Maradi } & \multicolumn{2}{|c|}{ Zinder } & \multicolumn{2}{|c|}{ Agadez } \\
\hline & Coef. & $p$ val & Coef. & $p$ val & Coef. & $p$ val & Coef. & $p$ val \\
\hline$\beta_{0}$ & -1.1 & 0.00 & -0.48 & 0.00 & -0.336 & 0.00 & -0.535 & 0.038 \\
\hline$\beta_{1}$ & $4.3 e-6$ & 0.00 & $2.7 e-6$ & 0.00 & $1.6 e-6$ & 0.00 & $2.4 e-6$ & 0.00 \\
\hline$\beta_{2}$ & 0.042 & 0.00 & 0.016 & 0.00 & 0.011 & 0.00 & 0.0115 & 0.00 \\
\hline$\beta_{3}$ & 0.003 & 0.00 & 0.0012 & 0.00 & 0.001 & 0.00 & 0.0014 & 0.19 \\
\hline$\beta_{4}$ & -0.008 & 0.03 & -0.0016 & 0.27 & $7 e-4$ & 0.48 & $5 e-4$ & 0.23 \\
\hline$\beta_{5}$ & -0.016 & 0.03 & -0.010 & 0.02 & -0.01 & 0.00 & -0.0053 & 0.29 \\
\hline$\beta_{6}$ & $5.3 e-5$ & 0.55 & $-9.9 e-5$ & 0.37 & $-6.2 e-5$ & 0.44 & $6 e-4$ & 0.14 \\
\hline$\beta_{7}$ & 0.52 & 0.08 & 0.31 & 0.08 & 0.26 & 0.03 & 0.36 & 0.29 \\
\hline \multicolumn{9}{|l|}{ Regression statistics } \\
\hline$R^{2}$ & 0.87 & & \multicolumn{2}{|c|}{0.854} & \multicolumn{2}{|c|}{0.833} & \multicolumn{2}{|c|}{0.551} \\
\hline Pro. (F. stat) & 0.000 & & \multicolumn{2}{|c|}{0.000} & \multicolumn{2}{|c|}{0.000} & \multicolumn{2}{|c|}{0.000} \\
\hline MAPE (\%) & \multicolumn{2}{|c|}{7.67} & \multicolumn{2}{|c|}{9.84} & \multicolumn{2}{|c|}{9.63} & \multicolumn{2}{|c|}{14.54} \\
\hline
\end{tabular}

Table 4: Results for model 2 for Niamey, Maradi, Zinder, and Agadez.

\begin{tabular}{|c|c|c|c|c|c|c|c|c|}
\hline \multirow{2}{*}{ Variables } & \multicolumn{2}{|c|}{ Niamey } & \multicolumn{2}{|c|}{ Maradi } & \multicolumn{2}{|c|}{ Zinder } & \multicolumn{2}{|c|}{ Agadez } \\
\hline & Coef. & $p$ val & Coef. & $p$ val & Coef. & $p$ val & Coef. & $p$ val \\
\hline$\beta_{0}^{\prime}$ & -0.91 & 0.00 & -0.443 & 0.00 & -0.13 & 0.12 & -0.5252 & 0.031 \\
\hline$\beta_{1}^{\prime}$ & $4.5 e-6$ & 0.00 & $2.9 e-6$ & 0.00 & $1.6 e-6$ & 0.00 & $2.5 e-6$ & 0.00 \\
\hline$\beta_{2}^{\prime}$ & 0.03 & 0.00 & 0.013 & 0.00 & 0.0078 & 0.00 & 0.01 & 0.00 \\
\hline$\beta_{3}^{\prime}$ & -0.018 & 0.00 & -0.002 & 0.07 & -0.0012 & 0.26 & $1.3 e-3$ & 0.52 \\
\hline$\beta_{4}^{\prime}$ & 0.0024 & 0.7 & -0.0023 & 0.55 & -0.0017 & 0.53 & -0.0045 & 0.45 \\
\hline$\beta_{5}^{\prime}$ & $-1.14 e-5$ & 0.9 & $-1 e-4$ & 0.13 & $-1.6 . e-5$ & 0.81 & $8 e-4$ & 0.14 \\
\hline$\beta_{6}^{\prime}$ & 0.18 & 0.45 & 0.054 & 0.76 & -0.096 & 0.41 & 0.26 & 0.39 \\
\hline \multicolumn{9}{|c|}{ Regression statistics } \\
\hline$R^{2}$ & 0.852 & & \multicolumn{2}{|c|}{0.834} & \multicolumn{2}{|c|}{0.78} & \multicolumn{2}{|c|}{0.549} \\
\hline Pro. (F. stat) & 0.000 & & \multicolumn{2}{|c|}{0.000} & \multicolumn{2}{|c|}{0.000} & \multicolumn{2}{|c|}{0.000} \\
\hline MAPE (\%) & \multicolumn{2}{|c|}{8.23} & \multicolumn{2}{|c|}{10.35} & \multicolumn{2}{|c|}{12.2} & \multicolumn{2}{|c|}{15.43} \\
\hline
\end{tabular}

Table 5: Results for model 3 for Niamey, Maradi, Zinder, and Agadez.

\begin{tabular}{|c|c|c|c|c|c|c|c|c|}
\hline \multirow{2}{*}{ Variables } & \multicolumn{2}{|c|}{ Niamey } & \multicolumn{2}{|c|}{ Maradi } & \multicolumn{2}{|c|}{ Zinder } & \multicolumn{2}{|c|}{ Agadez } \\
\hline & Coef. & $p$ val & Coef. & $p$ val & Coef. & $p$ val & Coef. & $p$ val \\
\hline$\beta^{\prime \prime}{ }_{0}$ & 0.168 & 0.22 & -0.006 & 0.94 & 0.14 & 0.02 & -0.171 & 0.40 \\
\hline$\beta_{1}^{\prime \prime}$ & $4.5 e-6$ & 0.00 & $3 e-6$ & 0.00 & $1.6 e-6$ & 0.00 & $2.7 e-6$ & 0.00 \\
\hline$\beta_{2}^{\prime \prime}$ & -0.0024 & 0.34 & -0.0021 & 0.09 & $-1.9 e-4$ & 0.03 & $-3.5 e-3$ & 0.07 \\
\hline$\beta_{3}^{\prime}$ & -0.028 & 0.00 & -0.004 & 0.00 & $-2.6 e-4$ & 0.02 & $-1.8 e-3$ & 0.41 \\
\hline$\beta_{4}^{\prime \prime}$ & 0.056 & 0.00 & 0.019 & 0.00 & 0.0114 & 0.00 & 0.014 & 0.00 \\
\hline$\beta^{\prime \prime}{ }_{5}$ & $8.9 e-5$ & 0.76 & $-3 e-4$ & 0.00 & $-1 e-4$ & 0.08 & $3 e-4$ & 0.36 \\
\hline$\beta_{6}^{\prime}$ & -1.46 & 0.00 & -0.636 & 0.00 & 0.09 & 0.00 & -0.123 & 0.65 \\
\hline \multicolumn{9}{|c|}{ Regression statistics } \\
\hline$R^{2}$ & 0.78 & & \multicolumn{2}{|c|}{0.80} & \multicolumn{2}{|c|}{0.833} & \multicolumn{2}{|c|}{0.531} \\
\hline Pro. (F. stat) & \multicolumn{2}{|c|}{0.00} & \multicolumn{2}{|c|}{0.000} & \multicolumn{2}{|c|}{0.000} & \multicolumn{2}{|c|}{0.000} \\
\hline MAPE (\%) & \multicolumn{2}{|c|}{9.79} & \multicolumn{2}{|c|}{11.13} & \multicolumn{2}{|c|}{12.96} & \multicolumn{2}{|c|}{16.15} \\
\hline
\end{tabular}


Homegeneity of the variance

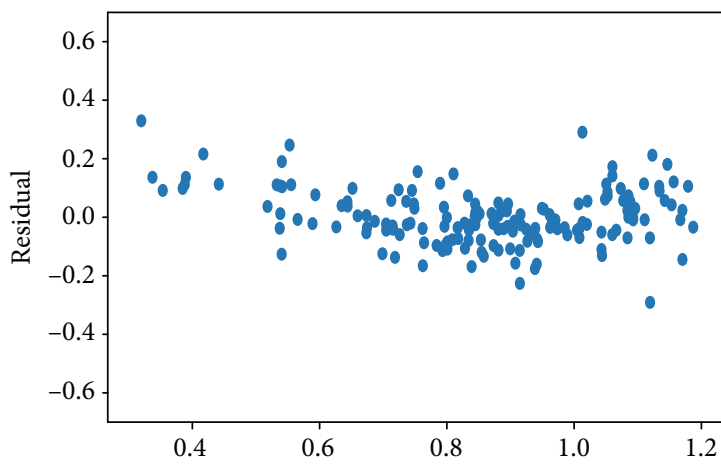

(a) Niamey

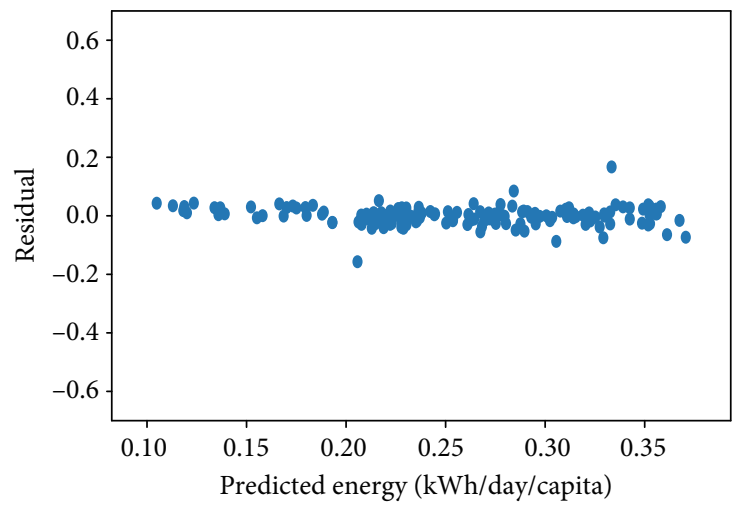

(c) Zinder

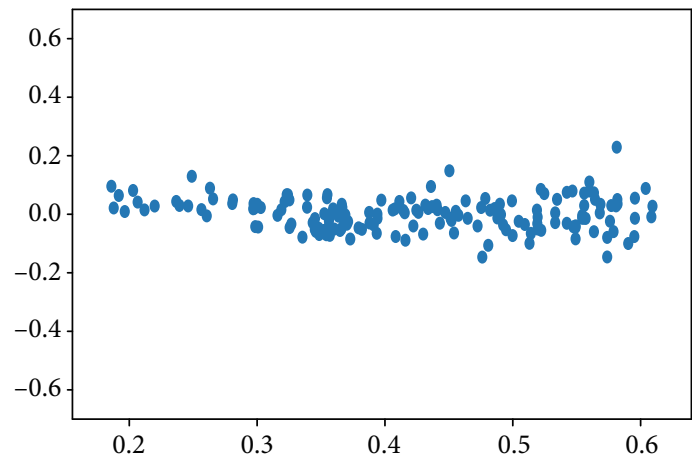

(b) Maradi

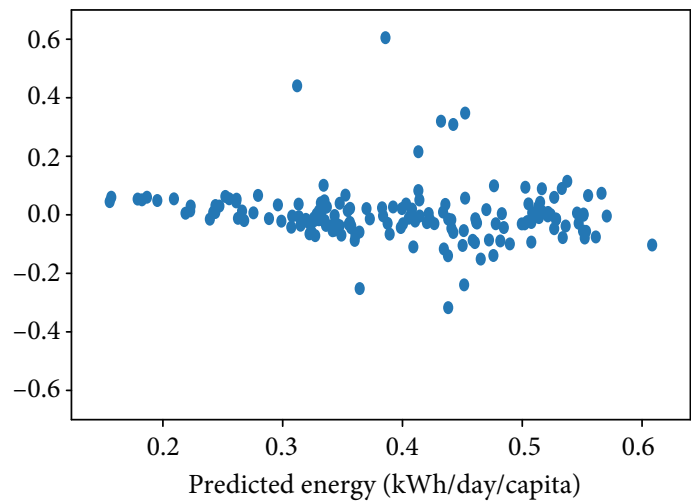

(d) Agadez

FIgURE 6: Residual plots of the best-fitted model for Niamey, Maradi, Zinder, and Agadez.

2.3. Seasonal Pattern of the Mean Absolute Percentage Errors (MAPEs). As stated, earlier model 1 performs better than model 2 and model 3. However, the influence of climate variables becomes more evident when the error estimates for individual months are considered. Figure 7 shows the monthly MAPE values for the three models. From a general point of view, model 1 performs better than the two other models. In addition, the MAPEs differ from the month and the city considered. For instance, for Niamey, all the models perform well compared to the other cities. The models show very low values of MAPEs (<2\%) for February, March, April, July, September, October, and December. In other words, in these months, any of the combination of variables can be successfully used to predict the electricity consumption in Niamey. Conversely, for May, June, and November, the models depict high values of MAPEs $(>3 \%)$. It is also worth noting that the use of HI or DI instead of Tmean and RH could yield to a good estimate in some months. This is the case for May and August where the use of heat indices resulted to a minimum MAPE than that of Tmean and $\mathrm{RH}$.

For the other cities, the MAPEs are relatively higher than that of Niamey, suggesting the impacts of climate variables are more pronounced in Niamey than the other cities. This could be explained by the fact that Niamey is the largest city in Niger accounting about $40 \%$ of the urban population. Indeed, according to Valor et al. [13], climate influences electricity consumption through the response of people to weather. That is, depending on the weather condition, people will increase or decrease the use of electric heating or cooling devices. Consequently, the higher the population, the higher the influence of climate on electricity consumption.

\section{Conclusion}

As part of the efforts to anticipate the impact of climate change on the energy sector in Niger, this study examines the influence of weather variables on electricity consumption in four major cities in Niger using the multiple linear regression models and a set of weather parameters. Three different regression models are derived for the weather parameters. Finally, the accuracy of the model is evaluated using the coefficient of determination $R^{2}$ and the mean absolute percentage errors. The results obtained are summarized below:

(i) The electricity consumption in Niger varies both seasonally and year to year. The former is attributed to the socioeconomic development while the former is due to prevailing weather conditions

(ii) Temperature and GDP/capita are the most influential factors that influence the electricity consumption of the four cities

(iii) Model 1 was found to be the best model with $R^{2}$ equals to $0.87,0.854,0.833$, and 0.551 for Niamey, 

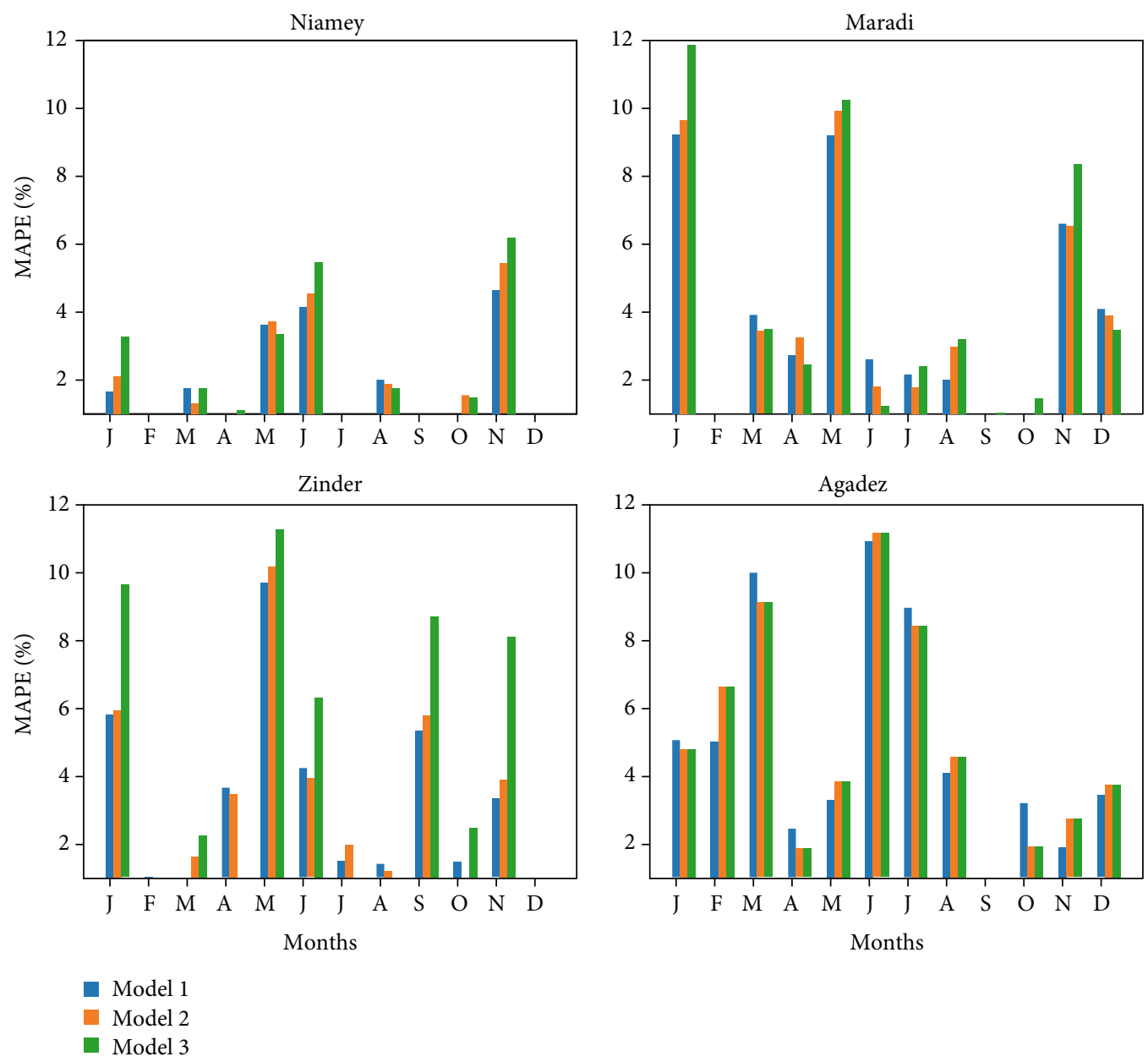

Figure 7: MAPE for individual months for Niamey, Maradi, Zinder, and Agadez.

Maradi, Zinder, and Agadez. The MAPEs are, respectively, 7.67, 9.84, 9.63, and 14.54

(iv) Precipitation and clearness index are found to be not statistically significant at $95 \%$ confidence level for all the cities. However, in addition to these variables, the wind speed and radiation are also not significant for cities Maradi, Zinder, and Agadez

In order to improve the ability of this study, future work could also include the influence of urbanization, electricity price, and energy efficiency in the models.

\section{Data Availability}

The data will be made available upon request.

\section{Conflicts of Interest}

The author declares that he has no conflicts of interest.

\section{References}

[1] J. L. Fan, B. J. Tang, H. Yu, Y. B. Hou, and Y. M. Wei, “Impacts of socioeconomic factors on monthly electricity consumption of China's sectors," Natural Hazards, vol. 75, no. 2, pp. 2039-2047, 2015.

[2] Z. Guo, K. Zhou, C. Zhang, X. Lu, W. Chen, and S. Yang, "Residential electricity consumption behavior: influencing factors, related theories and intervention strategies," Renewable and Sustainable Energy Reviews, vol. 81, pp. 399-412, 2018.

[3] T. S. A. Loi and J. L. Ng, "Analysing households' responsiveness towards socio-economic determinants of residential electricity consumption in Singapore," Energy Policy, vol. 112, no. October 2016, pp. 415-426, 2018.

[4] A. Pardo, V. Meneu, and E. Valor, "Temperature and seasonality influences on Spanish electricity load," Energy Economics, vol. 24, no. 1, pp. 55-70, 2002.

[5] B. E. Psiloglou, C. Giannakopoulos, S. Majithia, and M. Petrakis, "Factors affecting electricity demand in Athens, Greece and London, UK: a comparative assessment," Energy, vol. 34, no. 11, pp. 1855-1863, 2009.

[6] D. Sailor, "Relating residential and commercial sector electricity loads to climate- evaluating state level sensitivities and vulnerabilities," Energy, vol. 26, no. 7, pp. 645-657, 2001.

[7] Y. Akil and H. Miyauchi, "Seasonal peak characteristic comparison analysis by hourly electricity demand model," International Journal of Energy and Power Engineering, vol. 3, no. 3, pp. 132-138, 2014. 
[8] M. Bessec and J. Fouquau, "The non-linear link between electricity consumption and temperature in Europe: a threshold panel approach," Energy Economics, vol. 30, no. 5, pp. 27052721, 2008.

[9] H. Cho, Y. Goude, X. Brossat, and Q. Yao, "Modeling and forecasting daily electricity load curves: a hybrid approach," Journal of the American Statistical Association, vol. 108, no. 501, pp. 7-21, 2013.

[10] A. Georgantopoulos and A. Tsamis, "The relationship between energy consumption and GDP: a causality analysis on Balkan countries," European Journal of Scientific Research, vol. 61, no. 3, pp. 372-380, 2011.

[11] S. Jovanović, S. Savić, M. Bojić, Z. Djordjević, and D. Nikolić, "The impact of the mean daily air temperature change on electricity consumption," Energy, vol. 88, pp. 604609, 2015.

[12] H. Yi-Ling, M. Hai-Zhen, D. Guang-Tao, and S. Jun, "Influences of urban temperature on the electricity consumption of Shanghai," Advances in Climate Change Research, vol. 5, no. 2, pp. 74-80, 2014.

[13] E. Valor, V. Meneu, and V. Caselles, "Daily air temperature and electricity load in Spain," Journal of applied Meteorology, vol. 40, no. 8, pp. 1413-1421, 2001.

[14] M. A. Brown, M. Cox, B. Staver, and P. Baer, "Modeling climate-driven changes in U.S. buildings energy demand," Climatic Change, vol. 134, no. 1-2, pp. 29-44, 2016.

[15] O. Büyükalaca, H. Bulut, and T. Yılmaz, "Analysis of variablebase heating and cooling degree-days for Turkey," Applied Energy, vol. 69, no. 4, pp. 269-283, 2001.

[16] P. Holtedahl and F. L. Joutz, "Residential electricity demand in Taiwan," Energy Economics, vol. 26, no. 2, pp. 201-224, 2004.

[17] C. L. Hor, S. J. Watson, and S. Majithia, "Analyzing the impact of weather variables on monthly electricity demand," in IEEE Transactions on Power Systems, vol. 20, no. 4, pp. 2078-2085, 2005.

[18] K. P. Moustris, P. T. Nastos, A. Bartzokas, I. K. Larissi, P. T. Zacharia, and A. G. Paliatsos, "Energy consumption based on heating/cooling degree days within the urban environment of Athens, Greece," Theoretical and Applied Climatology, vol. 122, no. 3-4, pp. 517-529, 2015.

[19] S. Avdakovic, A. Ademovic, and A. Nuhanovic, "Insight into the properties of the UK power consumption using a linear regression and wavelet transform approach," 2013, http://arxiv.org/abs/1308.5572.

[20] O. Olanrewaju, L. Munda, and A. Jimoh, Understanding the Impacts of GDP and Population in South Africa's Energy Consumption, EWRM, Africa, 2014.

[21] M. Ali, M. J. Iqbal, and M. Sharif, "Relationship between extreme temperature and electricity demand in Pakistan," International Journal of Energy and Environmental Engineering, vol. 4, no. 1, p. 36, 2013.

[22] J. A. Azevedo, L. Chapman, and C. L. Muller, "Critique and suggested modifications of the degree days methodology to enable long-term electricity consumption assessments: a case study in Birmingham, UK," Meteorological Applications, vol. 22, no. 4, pp. 789-796, 2015.

[23] R. V. Jones, A. Fuertes, and K. J. Lomas, "The socio-economic, dwelling and appliance related factors affecting electricity consumption in domestic buildings," Renewable and Sustainable Energy Reviews, vol. 43, pp. 901-917, 2015.
[24] K. Kandananond, "Forecasting electricity demand in Thailand with an artificial neural network approach," Energies, vol. 4, no. 8, pp. 1246-1257, 2011.

[25] A. A. Salehizade, M. Rahmanian, M. Farajzadeh, and A. Ayoubi, "Analysis of temperature changes on electricity consumption in Fars province," Mediterranean Journal of Social Sciences, vol. 6, 2015.

[26] F. Apadula, A. Bassini, A. Elli, and S. Scapin, "Relationships between meteorological variables and monthly electricity demand," Applied Energy, vol. 98, pp. 346-356, 2012.

[27] NIGELEC, NIGELEC, 2016, Retrieved 2016, from http://www .nigelec.ne/.

[28] NASA, NASA Power Agroclimatology, 2018, Retrieved from NASA/POWER Agroclimatology Daily Averaged Data: http:// power.larc.nasa.gov/common/AgroclimatologyMethodology/ Agrold0_Methodology_Content.html.

[29] R. Steadman, "The assessment of sultriness. Part I: a temperature-humidity index based on human physiology and clothing science," Journal of Applied Meteorology, vol. 18, no. 7, pp. 861-873, 1979.

[30] A. Bonkaney, S. Madougou, and R. Adamou, "Impacts of Cloud Cover and Dust on the Performance of Photovoltaic Module in Niamey," Journal of Renewable Energy, vol. 2017, Article ID 9107502, 8 pages, 2017.

[31] S. Arlot and A. Celisse, "A survey of cross-validation procedures for model selection," Statistics Surveys, vol. 4, pp. 4079, 2010.

[32] L. Feng, A. Lin, L. Wang, W. Qin, and W. Gong, "Evaluation of sunshine-based models for predicting diffuse solar radiation in China," Renewable and Sustainable Energy Reviews, vol. 94, pp. 168-182, 2018.

[33] W. Qin, L. Wang, A. Lin et al., "Comparison of deterministic and data-driven models for solar radiation estimation in China," Renewable and Sustainable Energy Reviews, vol. 81, no. May 2017, pp. 579-594, 2018.

[34] L. Wang, O. Kisi, M. Zounemat-Kermani, G. A. Salazar, Z. Zhu, and W. Gong, "Solar radiation prediction using different techniques: model evaluation and comparison," Renewable and Sustainable Energy Reviews, vol. 61, pp. 384-397, 2016.

[35] M. Yuan, L. Wang, A. Lin, Z. Liu, Q. Li, and S. Qu, "Vegetation green up under the influence of daily minimum temperature and urbanization in the Yellow River Basin, China," Ecological Indicators, vol. 108, 2020. 